\title{
Constitutional CHEK2 mutations are infrequent in early-onset and familial breast/ovarian cancer patients from Pakistan
}

\author{
Muhammad U Rashid ${ }^{1,2}$, Noor Muhammad ${ }^{1}$, Saima Faisal ${ }^{1}$, Asim Amin $^{3}$ and Ute Hamann ${ }^{2 *}$
}

\begin{abstract}
Background: Less than 20\% of Pakistani women with early-onset or familial breast/ovarian cancer harbor germ line mutations in the high-penetrance genes BRCA1, BRCA2 and TP53. Thus, mutations in other genes confer genetic susceptibility to breast cancer, of which CHEK2 is a plausible candidate. CHEK2 encodes a checkpoint kinase, involved in response to DNA damage.
\end{abstract}

Methods: In the present study we assessed the prevalence of CHEK2 germ line mutations in 145 BRCA1/2-negative early-onset and familial breast/ovarian cancer patients from Pakistan (Group 1). Mutation analysis of the complete CHEK2 coding region was performed using denaturing high-performance liquid chromatography analysis, followed by DNA sequencing of variant fragments.

Results: Two potentially deleterious missense mutations, c.275C > G (p.P92R) and c.1216C>T, (p.R406C), were identified (1.4\%). The c.275C>G mutation is novel and has not been described in other populations. It was detected in a 30-year-old breast cancer patient with a family history of breast and multiple other cancers. The c.1216C>T mutation was found in a 34-year-old ovarian cancer patient from a family with two breast cancer cases. Both mutations were not detected in 229 recently recruited BRCA1/2-negative high risk patients (Group 2).

Conclusion: Our findings suggest that CHEK2 mutations may not contribute significantly to breast/ovarian cancer risk in Pakistani women.

Keywords: CHEK2, Germ line mutations, Early-onset and familial breast cancer, Pakistan

\section{Background}

DNA damage results in activation of cell-cycle checkpoints that inhibit cell proliferation and initiate DNA repair. Impaired function of such checkpoints can lead to genomic instability and susceptibility to cancer. CHEK2 (cell cycle checkpoint kinase 2, OMIM \#604373) is a G2 checkpoint serine/threonine kinase that acts as a tumor suppressor in the nucleus in response to DNA doublestrand breakage [1]. The CHEK2 protein is phosphorylated by ataxia-telangiectasia-mutated (ATM) [2] and subsequently phosphorylates critical cell-cycle proteins including TP53, CDC25C, CDC25A and BRCA1, promoting cell cycle arrest, apoptosis and DNA repair [3-6].

\footnotetext{
* Correspondence: u.hamann@dkfz-heidelberg.de

${ }^{2}$ Deutsches Krebsforschungszentrum (DKFZ), Molecular Genetics of Breast Cancer, Heidelberg, Germany

Full list of author information is available at the end of the article
}

Recent studies have indicated that CHEK2 functions as a moderately effective cancer susceptibility gene; mutations in CHEK2 predispose individuals to breast cancer [7-10] as well cancer of other sites [11-13]. Thus far, five deleterious recurrent mutations in CHEK2 have been identified that confer about twofold elevated risk of breast cancer in unselected female population. These include the truncating mutation CHEK2 c.1100delC $[14,15]$, the missense mutations p.I157T and p.S428F $[7,16]$, the splice site mutation c.IVS $2+1 \mathrm{G}>\mathrm{A}[7,17]$ and the large genomic 5,395 bp deletion (del5395) [18]. For carriers of the c.1100delC mutation, even higher risk of up to three to five fold was observed among early-onset and familial breast cancer patients $[14,15]$.

The frequencies of these mutations have been shown to vary widely with geographic distribution and ethnicity [19-32]. The prevalence of c.1100delC ranged from being

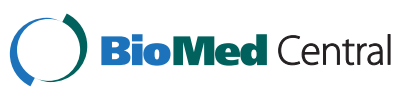


virtually absent in South-European to $1.5 \%$ in populations from North-Europe [33], while it was not detected in breast cancer patients from Asia, including China, Korea, Malaysia, Singapore, Japan, the Philippines, India and Pakistan [20-23,28-32]. The variants c.IVS2 +1G>A and del5395 were identified in Poland [7,18], Belarus [17,34], Russia [35] and Czech Republic [36] with a frequency of $0.7 \%-1.1 \%$ and $0.9 \%-1.3 \%$, respectively; p.S428F was identified in the Ashkenazi Jewish population with a frequency of $2.9 \%$ [16] and p.I157T in Finland with a prevalence of $7.4 \%[26]$.

The role of CHEK2 mutations in breast cancer predisposition has been investigated previously in several studies conducted in Asia. Whereas most studies restricted the analysis to the CHEK2 c.1100delC mutation [20-23,28-32], the study performed by Liu and colleagues included the entire gene [37]. In this study conducted in China a novel pathogenic missense mutation, p.H371Y, was identified in familial and unselected breast cancer cases and controls with a frequency of $4.2 \%, 1.8 \%$ and $0.7 \%$, respectively. These results suggest that CHEK2 germ line mutations may contribute to breast cancer susceptibility in the Chinese population and point to the need of more whole mutational screens in other Asian populations.

Given the paucity of data on genetic variability of CHEK2 in Asian populations coupled with the fact that less than $20 \%$ of Pakistani women with early-onset or familial breast/ovarian cancer can be attributed to germ line mutations in BRCA1, BRCA2 and TP53 [38,39], we assessed the prevalence of $C H E K 2$ mutations in 145 highrisk $B R C A 1 / 2$-negative breast/ovarian cancer patients from Pakistan (Group 1). Comprehensive mutation analysis of the entire coding region and the exon-intron junctions of the CHEK2 gene were performed. An additional group of 229 high-risk BRCA1/2-negative breast/ovarian cancer patients (Group 2) were screened for the identified CHEK2 mutations.

\section{Methods}

\section{Study subjects}

The study included index patients from 145 breast and/or ovarian cancer families who have been assessed and confirmed to be negative for $B R C A 1 / 2$ germ line mutations and described previously (Group 1) [38]. After identification of mutations from the entire coding region of the CHEK2 gene in this cohort, an additional cohort of 229 $B R C A 1 / 2$-negative high-risk patients was screened for the two identified mutations (Group 2). The index cases were identified using the following criteria: i) families with one female breast cancer diagnosed $\leq 30$ years of age, ii) families with two first- or second-degree (through a male) female relatives diagnosed with breast cancer; at least one diagnosed $\leq 50$ years of age, iii) families with at least three cases of breast cancer; at least one diagnosed $\leq 50$ years of age, iv) families with one male breast cancer case diagnosed at any age, v) families with at least one female breast cancer and one ovarian cancer at any age, vi) families with one ovarian cancer diagnosed $\leq 45$ years of age and vii) families with at least two ovarian cancers; at least one diagnosed $\leq 45$ years of age. Breast and ovarian cancer in the same patient were counted as two independent cases. The number of index cases by phenotype for Group 1 and Group 2 are shown in Table 1.

Control population comprised 150 healthy females of Pakistani origin. These were either attendants of hospital registered patients or visiting the cancer centre for medical reasons other than cancer. All study participants were furnished with and signed an informed written consent. The study was approved by the Institutional Review Board of the SKMCH \& RC.

\section{Mutation screening}

Genomic DNA was extracted as previously described [38]. The entire coding region and exon-intron junctions of the CHEK2 gene (Genbank accession number NM_007194.2) were screened in the 145 index patients using denaturing high-performance liquid chromatography (DHPLC) analysis. DHPLC analysis was carried out with the WAVE system (Transgenomics, Omaha, NE). Since multiple homologous copies are present for exons 10-14 of this gene, a nested PCR approach was employed as previously described [40]. PCR-primer pairs and DHPLC running conditions for exon 1 and exons 4-14 were according to Dufault and colleagues [41] and for exons 2 and 3 according to Kleibl and colleagues [42]. When available, a mutation positive control for each exon was included in the DHPLC analyses.

The presence of the CHEK2 mutations identified in Group 1 was subsequently assessed in the 229 BRCA1/ 2-negative high-risk cases of Group 2 and in 150 healthy female controls.

\section{DNA sequence analysis}

Each sample showing variants detected by DHPLC analysis was sequenced using an automated DNA CEQ 8000 sequencer (Beckman, Hilden, Germany) according to the manufacturers' instructions. Bi-directional genomic DNA sequencing was performed to verify the presence of a mutation.

\section{In silico analyses}

CHEK2 missense variants (p.P92R; p.R406C) were analyzed for their potential effect on protein function using the default settings of web tools Align-GVGD (http:// agvgd.iarc.fr/agvgd_input.php), PolyPhen2 (http://genetics.bwh.harvard.edu/pph2), SIFT (http://sift.jcvi.org) and SNAP (http://www.rostlab.org/services/snap). 
Table 1 Description of index cases screened for CHEK2 mutations

\begin{tabular}{|c|c|c|c|c|c|c|}
\hline \multirow{2}{*}{$\begin{array}{l}\text { Cancer type } \\
\text { of index case }\end{array}$} & \multirow[t]{2}{*}{ Phenotype of families ${ }^{a}$} & \multirow{2}{*}{$\begin{array}{l}\text { Number of } \\
\text { families }\end{array}$} & \multicolumn{2}{|c|}{ Index cases } & \multirow{2}{*}{$\begin{array}{c}\text { Mean age of } \\
\text { index cases } \\
\text { in years } \\
\text { (age range) }\end{array}$} & \multirow{2}{*}{$\begin{array}{c}\text { Cases with } \\
\text { mutations } \\
\text { N (\%) }\end{array}$} \\
\hline & & & Unilateral BC & Bilateral BC & & \\
\hline \multicolumn{7}{|l|}{ Group I } \\
\hline \multicolumn{7}{|l|}{ Female cases } \\
\hline $\mathrm{BC}$ & Early onset BC (1 case $\leq 30$ years) & 66 & 66 & - & $27.2(22-30)$ & $1(1.5)$ \\
\hline$B C$ & HBC ( 2 cases, $\geq 1$ diagnosed $\leq 50$ years) & 30 & 17 & 13 & $34.2(22-48)$ & $0(0)$ \\
\hline $\mathrm{BC}$ & HBC ( $\geq 3$ cases, $\geq 1$ diagnosed $\leq 50$ years) & 9 & 5 & 4 & $38.1(24-70)$ & $0(0)$ \\
\hline$B C$ & $\mathrm{HBOC}(\geq 2$ cases $)$ & 2 & 2 & - & $41.5(35-48)$ & $0(0)$ \\
\hline$B C \& O C^{b}$ & HBOC ( $\geq 2$ cases $)$ & 4 & 3 & 1 & $31.2(29-34)$ & $0(0)$ \\
\hline OC & $\mathrm{HBOC}(\geq 2$ cases $)$ & 2 & - & - & $31(28-34)$ & $1(50)$ \\
\hline OC & Early onset OC ( 1 case $\leq 45$ years) & 19 & - & - & $33.2(22-45)$ & $0(0)$ \\
\hline OC & HOC ( 2 cases, $\geq 1$ diagnosed $\leq 45$ years) & 2 & - & - & $34(31-37)$ & $0(0)$ \\
\hline \multicolumn{7}{|l|}{ Male cases } \\
\hline$B C$ & Male BC & 11 & 11 & - & $48(30-73)$ & $0(0)$ \\
\hline All cases $^{c}$ & & 145 & 104 & 18 & & $2(1.4)$ \\
\hline \multicolumn{7}{|l|}{ Group II } \\
\hline \multicolumn{7}{|l|}{ Female cases } \\
\hline $\mathrm{BC}$ & Early onset BC (1 case $\leq 30$ years) & 103 & 103 & - & $27.1(19-30)$ & $0(0)$ \\
\hline $\mathrm{BC}$ & HBC ( 2 cases, $\geq 1$ diagnosed $\leq 50$ years) & 55 & 49 & 6 & $40.8(19-61)$ & $0(0)$ \\
\hline$B C$ & HBC ( $\geq 3$ cases, $\geq 1$ diagnosed $\leq 50$ years) & 53 & 47 & 6 & $44.4(26-73)$ & $0(0)$ \\
\hline BC & $\mathrm{HBOC}(\geq 2$ cases $)$ & 8 & 7 & 1 & $49(26-67)$ & $0(0)$ \\
\hline$B C \& O C^{b}$ & HBOC ( $\geq 2$ cases $)$ & 3 & 2 & 1 & 45.6 (30-59) & $0(0)$ \\
\hline OC & HBOC ( $\geq 2$ cases) & 5 & - & - & $43.2(33-60)$ & $0(0)$ \\
\hline OC & Early onset OC ( 1 case $\leq 45$ years) & 2 & - & - & $30.5(25-36)$ & $0(0)$ \\
\hline All cases $^{d}$ & & 229 & 208 & 14 & & $0(0)$ \\
\hline
\end{tabular}

$B C$, breast cancer; $H B C$, hereditary breast cancer; $H B O C$, hereditary breast and ovarian cancer; $H O C$, hereditary ovarian cancer; $O C$, ovarian cancer.

a see "Study subjects in Method section".

${ }^{b}$ Breast and ovarian cancer in the same patient were counted as two independent cases.

Including 111 female BCs, 11 male BCs and 27 OCs.

${ }^{d}$ Including 222 female BCs and 10 OCs.

\section{Results}

We studied 145 unrelated affected index patients from Pakistani breast and/or ovarian cancer families all of whom have previously been tested and found to be negative for BRCA1/2 germ line mutations (Group 1). The median age of onset of disease was 29 years (range 22-70) for female breast cancer $(\mathrm{n}=111), 45$ years (range 30-73) for male breast cancer $(\mathrm{n}=11)$ and 33 years (range 22-45) for ovarian cancer $(n=27)$. Eighteen of 111 (16.2\%) women were diagnosed with bilateral breast cancer. Five cases reported a relative affected with colorectal or prostate cancer.

The joint approach of DHPLC and DNA sequencing analysis revealed ten CHEK2 sequence variants: one silent mutation, three missense mutations and six intronic variants (Table 2).

Two missense potentially functional mutations, c. $275 \mathrm{C}>\mathrm{G}$ (p.P92R) and c.1216C $>$ T (p.R406C) were identified in 2 out of the 145 (1.4\%) breast/ovarian cancer families (Table 1). c.275C $>$ G (p.P92R) is a novel mutation that has not previously been reported in other populations (Additional file 1: Figure S1). It was detected in a 30year-old early-onset breast cancer patient (IV:3) of Punjabi ethnicity, who presented with a grade 3 , lymph node positive, invasive ductal carcinoma, positive for expression of estrogen receptor (ER), progesterone receptor (PR) and epidermal growth factor receptor 2 (HER2) (data not shown). The mutation was also found in another distant paternal female relative, who was diagnosed with breast cancer at 53 years of age (III:9) (Additional file 2: Figure S2A). On the paternal side of the index patient, two more female breast cancers, one bilateral disease diagnosed at 30 and 60 years of age and the other at unknown age, one intestinal cancer, one lung cancer, one cancer of unknown type and one Hodgkin lymphoma were reported. To predict the 
Table 2 CHEK2 germ line mutations and nucleotide changes in non-BRCA1/2-associated early-onset and familial breast/ ovarian cancer patients from Pakistan

\begin{tabular}{|c|c|c|c|c|c|c|c|}
\hline \multirow[t]{3}{*}{ Location } & \multirow[t]{3}{*}{ Coding (c.) DNA sequence ${ }^{a}$} & \multirow[t]{3}{*}{ Effect } & \multirow[t]{3}{*}{ SNP Link ${ }^{b}$} & \multirow[t]{3}{*}{ Classification $^{c}$} & \multicolumn{3}{|c|}{ Prevalence } \\
\hline & & & & & \multirow{2}{*}{$\begin{array}{l}\text { Group } 1 \\
\text { Cases }(n=145) \\
n(\%)\end{array}$} & \multicolumn{2}{|l|}{ Group 2} \\
\hline & & & & & & $\begin{array}{l}\text { Cases }(\mathrm{n}=229) \\
\mathrm{n}(\%)\end{array}$ & $\begin{array}{l}\text { Controls }(n=150) \\
n(\%)\end{array}$ \\
\hline Exon 1 & c.252A>G (E84E) & Silent & rs1805129 & $P$ & $13(8.9)$ & $18(7.9)$ & $12(8.0)$ \\
\hline Exon 1 & c. $275 \mathrm{C}>\mathrm{G}(\mathrm{P} 92 \mathrm{R})$ & Missense & - & M & $1(0.7)$ & $0(0)$ & $0(0)$ \\
\hline Exon 10 & c.1216C>T (R406C) & Missense & - & M & $1(0.7)$ & $0(0)$ & $0(0)$ \\
\hline Exon 13 & c.1501G>A (E501K) & Missense & rs17883172 & $P$ & $3(2.1)$ & $1(0.4)$ & $0(0)$ \\
\hline Intron 1 & c.319+43_319+44insA & Intronic & rs17879991 & $P$ & $64(44.1)$ & - & $47(31.3)$ \\
\hline Intron 3 & c. $592+50 \mathrm{~A}>\mathrm{T}$ & Intronic & rs17881298 & $P$ & $1(0.7)$ & - & $0(0)$ \\
\hline Intron 4 & c.683 +119_683+122delATTT & Intronic & - & $\mathbf{P}$ & $2(1.4)$ & - & $1(0.7)$ \\
\hline Intron 4 & c.684-78_-100dup23 & Intronic & - & $P$ & $16(11.0)$ & - & $20(13.3)$ \\
\hline Intron 7 & c. $908+48$ dupA & Intronic & - & VUS & $1(0.7)$ & - & $0(0)$ \\
\hline Intron 13 & c. $1542+92$ dupA & Intronic & - & VUS & $1(0.7)$ & - & $0(0)$ \\
\hline
\end{tabular}

Novel germ line mutations and nucleotide changes are marked in bold.

$P$, polymorphism; $M$, mutation; VUS, variant of unknown significance.

${ }^{a}$ Nomenclature follows Human Genome Variation Society (HGVS) (http://www.hgvs.org). Numbering starts at the first A of the first coding ATG (located in exon 2) of NCBI GenBank Accession NM 007194.

b Link to NCBI SNP database (http://ncbi.nlm.nih.gov/projects/SNP/).

${ }^{c}$ Classification of missense mutations is based on in silico analyses.

significance of the novel mutation in silico analyses were performed using the computational tools AlignGVGD, PolyPhen2, SIFT and SNAP. The mutation was predicted to be likely pathogenic by PolyPhen 2 and SNAP.

The other missense mutation c.1216C>T (p.R406C) was found in a patient from Punjab, who was diagnosed with ovarian cancer at age 34 (IV:2). The mother of the index patient and a maternal aunt of the mother were diagnosed with breast cancer at 38 years of age and at unknown age, respectively (Additional file 2: Figure S2B). The mutation carrier presented with a high grade papillary serous carcinoma. This germ line mutation has previously been reported in two female breast cancer patients $[43,44]$ and was predicted to be likely pathogenic in silico [43].

Both missense mutations are rare as they were not detected in Group 2 that included 229 patients with $B R C A 1 / 2$-negative breast/ovarian cancer or the 150 healthy female controls indicating that they may be disease-causative.

Of the other described CHEK2 variants, the silent mutation, one missense mutation and three intronic variants have been previously classified as polymorphisms (Table 2). Three of these (c.252A $>$ G, c.319+43_319+44insA and c.592 $+50 \mathrm{~A}>\mathrm{T}$ ) have also been identified in the NHLBI Exome Sequencing Project (http://evs.gs.washington.edu/ EVS/). Three novel variants are located in introns and are deemed unlikely to have a functional effect.

\section{Discussion}

The relevance of CHEK2 mutations as a screening target for an elevated risk of breast cancer is of interest. Given the variability among different populations the frequency within a given population needs to be ascertained to qualify relevance. Our contribution to this area of investigation was to establish relevance in the $B R C A 1 / 2$-negative high-risk breast/ovarian cancer Pakistani population by assessing the prevalence of CHEK2 mutations. While only one Asian study conducted in China has investigated the frequency of CHEK2 germ line mutations using the whole gene screen [37], our study will provide additional information on genetic variability of the CHEK2 gene in an Asian population from Pakistan.

The risk conferred by CHEK2 germ line mutations to breast and ovarian cancer in Asian populations is not well defined since most studies have determined the frequency of the c.1100delC mutation but did not evaluate other mutations. This holds true for studies conducted in Korea [23], Malaysia [31], Singapore [28], Japan [21], China [22,32], India [29,30], Pakistan and the Philippines [20]. In the present study we investigated the entire CHEK2 coding sequence including the exon-intron junctions using DHPLC analysis followed by direct DNA sequencing of variant fragments. Two potentially deleterious missense mutations, novel p.P92R and p.R406C, were identified in two unrelated patients. Both mutations are rare as they were not detected in a second group of 229 $B R C A 1 / 2$-negative early-onset and familial breast/ovarian 
cancer patients and 150 healthy controls suggesting that they may be associated with the disease. Our findings suggest that CHEK2 missense mutations may not contribute significantly to breast/ovarian cancer susceptibility in Pakistan. In a study conducted in China that looked at CHEK2 mutations based on whole gene analysis, a novel recurrent missense mutation, p.H371Y, was identified in 5/118 (4.2\%) familial and 16/909 (1.8\%) unselected breast cancer patients and in 9/1,228 (0.7\%) controls [37]. The results of this study and the present one suggest that CHEK2 germ line mutations may contribute to breast cancer susceptibility in populations from East Asia, but may play a minor role in a South Asian population from Pakistan. Our data on the absence of the c.1100delC mutation in Pakistan are in line with those of previous studies [20-23,28-32] supporting the notion that c.1100delC does not contribute to breast cancer susceptibility in Asian populations.

In contrast to the single study of a whole CHEK2 gene screen in an Asian population, many studies have been performed in Caucasian populations reporting different mutations and mutation frequencies in the range from $0 \%$ to $12 \%$. In the French-Canadian population no mutations were detected in 25 (0\%) BRCA1/2-negative familial breast cancer patients [19]. In France mutations were found in 15/507 (2.9\%) BRCA1/2-negative familial breast cancer cases [25]. In the United States mutations were observed in $5 / 169$ (3\%) early-onset breast cancer patients ( $\leq 40$ years) [21] and in another study mutations were identified in 51/1,303 (3.9\%) early-onset patients ( $\leq 45$ years) from the United States, Canada and Australia [43]. The highest mutation frequencies were reported in 30/516 (5.8\%) BRCA1/2-negative familial breast cancer patients from Germany [41], 10/172 (5.8\%) Ashkenazi Jewish familial BRCA1/2-founder mutation-negative breast and/or ovarian cancer patients or unaffected women [45], 8/89 (8.9\%) familial breast cancer patients from the UK, North America and the Netherlands [46] and in 10/82 (12.2\%) familial BRCA1/2-founder mutationnegative breast and/or ovarian cancer patients from Finland [27].

Mutation screening was performed using the combined approach of DHPLC analysis followed by DNA sequencing of variant fragments. DHPLC has been commonly used for mutation screening of various genes as it is rapid, cost-effective and highly sensitive detecting 93 to $100 \%$ of mutations that were observed by DNA sequencing [47]. However, since the DHPLC mutation detection rate is not $100 \%$ for each gene, it cannot be ruled out that some mutations were missed. CHEK2 mutation analysis is hampered by the presence of multiple homologous copies for exons $10-14$ and requires an adapted primer design and amplification conditions. In the present study we employed a nested PCR strategy that specifically amplified the functional copy of the CHEK2 gene [40].

The CHEK2 mutation frequency of 2/145 (1.4\%) observed in this study may be an underestimate as the sensitivity of DHPLC can be below 100\% and screening for regulatory mutations residing outside the coding region and for large genomic rearrangements was not performed. Previously a large genomic deletion of 5,395 bp, which results in loss of exons 9 and 10, has been identified in two families of Czechoslovakian ancestry, in a series of Czech and Slovak breast cancer patients (8/631, $1.3 \%$ ) enriched for familial cases and was absent in 367 controls [36]. In Poland the same deletion was detected in $19 / 1,978$ (1.0\%) unselected breast cancer cases, 28/3,228 (0.9\%) early-onset cases and in 24/5,496 (0.4\%) controls [18]. Thus further analyses for genomic rearrangements in Asian populations may reveal additional CHEK2 mutations as well.

In the present study a novel missense mutation, p.P92R, was identified in a young Pakistani breast cancer patient of Punjabi origin from a family with multiple breast cancers, intestinal cancer, lung cancer, cancer of unknown type and Hodgkin lymphoma. The mutation was also found in another paternal female relative diagnosed with breast cancer at 53 years of age. Since CHEK2 is known to be a multi-organ cancer susceptibility gene [7], the mutation may have co-segregated with the disease in this family. However, this could not be tested since DNA samples of relevant family members were not available for analysis. The other mutation, p.R406C, was found in a young Punjabi patient diagnosed with ovarian papillary serous carcinoma, who reported a family history of breast cancer. The same mutation has previously been observed in a Spanish familial breast cancer patient and in an earlyonset breast cancer patient ( $\leq 45$ years) of unknown ancestry, but was absent in 400 healthy controls from Spain and 1,109 controls from Canada, the USA and Australia $[43,44]$. Due to the lack of DNA samples of relevant family members, co-segregation of this mutation with cancer could not be studied.

The breast tumor of the patient harboring the p.P92R missense mutation was positive for ER, which is consistent with previous findings that breast tumors linked with CHEK2 frame shift and missense mutations (c.1100delC, c.IVS2 +1G >A, del5395, p.I157T) are predominantly ERpositive [48-50]. Additionally, an association of the CHEK2 p.I157T missense mutation has been reported with lobular carcinoma [50,51]. This link was not observed with the novel p.P92R missense mutation in the present study given the only p.P92R-associated tumor was invasive ductal carcinoma. Given the solitary finding, no interpretation could be rendered.

Our study included cases and controls from only one ethnic group providing uniformity of subjects, adding to 
the robustness of data. All patients had been selected for $B R C A 1 / 2$ testing by virtue of having an early-onset of disease or a family history suggestive of hereditary breast/ovarian cancer [38]. Genetic variability in CHEK2 was analyzed in a whole gene screen and was not restricted to the few regions with known CHEK2 mutations. Limitations of the present study are that the functional effects p.P92R and p.R406C and the frequency of large genomic rearrangements were not investigated.

\section{Conclusions}

In this first study of the prevalence of CHEK2 germ line mutations in 145 BRCA1/2-negative early-onset and familial breast and/or ovarian cancer from Pakistan two potentially deleterious mutations were identified. Both mutations are rare as they were not found in 229 other high-risk patients. Our findings suggests that CHEK2 germ line mutations play a negligible role in early-onset and familial breast/ovarian cancer in Pakistan and imply that CHEK2 mutation screening of high-risk patients is not warranted in this population.

\section{Additional files}

Additional file 1: Figure S1. DNA mutation analysis of $C H E K 2$ C. $275 C>G$ (P92R). DNA sequencing chromatograms of the forward strand showing the region containing the $\mathrm{c} .275 \mathrm{C}>\mathrm{G}$ sequence of healthy control sample (A) and corresponding interval from DNA of a c.275C > G mutation carrier (B). The arrow indicates the position of the mutation in the chromatogram. S, C>G

Additional file 2: Figure S2. Pedigrees of CHEK2 C.275C>G (A) and c.1216C>T (B) mutation carrier Families 112 and 171. Circles are females, squares are males, and a diagonal slash indicates a deceased individual. Symbols with filled left upper quadrant: unilateral breast cancer. Symbols with filled upper half circle: bilateral breast cancer. Symbols with filled left lower quadrant: ovarian cancer. Symbols with filled right lower quadrant: cancer other than breast cancer, cancer type is indicated. Identification numbers of individuals are below the symbols. The index patient is indicated by an arrow. $A$, age; $B C$, breast cancer; $H D$, Hodgkin's disease; $O C$, ovarian cancer; $C A$, cancer; $D$, death. The numbers following these abbreviations indicate age at recruitment, age at cancer diagnosis and age at death. $M+$, mutation positive. $M$-, mutation negative.

\section{Abbreviations \\ CHEK2: Cell cycle checkpoint kinase 2 gene; DHPLC: Denaturing high- performance liquid chromatography.}

\section{Competing interests}

The authors declare that they have no competing interests.

\section{Authors' contributions}

MUR contributed to conception and design of the study, patient recruitment and data acquisition. In addition, he was involved in data analysis, interpretation and in drafting and revising the manuscript. NM performed the molecular analyses and contributed to data analysis and interpretation. SF was involved in patient recruitment and data acquisition. UH contributed to conception and design of the study, data analysis and interpretation and led the writing of the manuscript. All authors read and approved the final manuscript.

\section{Acknowledgements}

We are grateful to all family members for their participation in this study. We thank Zdenek Kleibl for DNA samples of CHEK2 mutation carriers. This study was supported by the Deutsches Krebsforschungszentrum and the Shaukat Khanum Memorial Cancer Hospital and Research Centre. MUR was supported by an UICC International Cancer Technology Transfer Fellowship for one month.

\section{Author details}

'Shaukat Khanum Memorial Cancer Hospital and Research Centre (SKMCH \& RC), Lahore, Pakistan. ${ }^{2}$ Deutsches Krebsforschungszentrum (DKFZ), Molecular Genetics of Breast Cancer, Heidelberg, Germany. ${ }^{3}$ Levine Cancer Institute, Carolinas Medical Center, Charlotte, USA.

Received: 4 February 2013 Accepted: 22 May 2013 Published: 27 June 2013

\section{References}

1. Bartek J, Lukas J: Chk1 and Chk2 kinases in checkpoint control and cancer. Cancer Cell 2003, 3:421-429.

2. Matsuoka S, Rotman G, Ogawa A, Shiloh Y, Tamai K, Elledge SJ: Ataxia telangiectasia-mutated phosphorylates Chk2 in vivo and in vitro. Proc Natl Acad Sci USA 2000, 97:10389-10394.

3. Lee JS, Collins KM, Brown AL, Lee $\mathrm{CH}$, Chung JH: hCds1-mediated phosphorylation of BRCA1 regulates the DNA damage response. Nature 2000, 404:201-204.

4. Zeng Y, Forbes KC, Wu Z, Moreno S, Piwnica-Worms H, Enoch T: Replication checkpoint requires phosphorylation of the phosphatase $\mathrm{Cdc} 25$ by $\mathrm{Cds} 1$ or Chk1. Nature 1998, 395:507-510.

5. Chehab NH, Malikzay A, Appel M, Halazonetis TD: Chk2/hCds1 functions as a DNA damage checkpoint in G(1) by stabilizing p53. Genes Dev 2000, 14:278-288.

6. Falck J, Mailand N, Syljuasen RG, Bartek J, Lukas J: The ATM-Chk2-Cdc25A checkpoint pathway guards against radioresistant DNA synthesis. Nature 2001, 410:842-847.

7. Cybulski C, Gorski B, Huzarski T, Masojc B, Mierzejewski M, Debniak T, Teodorczyk U, Byrski T, Gronwald J, Matyjasik J, et al: CHEK2 is a multiorgan cancer susceptibility gene. Am J Hum Genet 2004, 75:1131-1135.

8. Meijers-Heijboer H, Van Den OA, Klijn J, Wasielewski M, De SA, Oldenburg R, Hollestelle A, Houben M, Crepin E, Van Veghel-Plandsoen M, et al: Low-penetrance susceptibility to breast cancer due to $\mathrm{CHEK} 2\left(^{*}\right) 1100 \mathrm{delC}$ in noncarriers of BRCA1 or BRCA2 mutations. Nat Genet 2002, 31:55-59.

9. Oldenburg RA, Kroeze-Jansema K, Kraan J, Morreau H, Klijn JG, Hoogerbrugge N, Ligtenberg MJ, van Asperen CJ, Vasen HF, Meijers C, et al: The CHEK2*1100delC variant acts as a breast cancer risk modifier in non-BRCA1/BRCA2 multiple-case families. Cancer Res 2003, 63:8153-8157.

10. Vahteristo P, Bartkova J, Eerola H, Syrjakoski K, Ojala S, Kilpivaara O, Tamminen A, Kononen J, Aittomaki K, Heikkila P, et al: A CHEK2 genetic variant contributing to a substantial fraction of familial breast cancer. Am J Hum Genet 2002, 71:432-438.

11. Dong $X$, Wang L, Taniguchi K, Wang X, Cunningham JM, McDonnell SK, Qian C, Marks AF, Slager SL, Peterson BJ, et al: Mutations in CHEK2 associated with prostate cancer risk. Am J Hum Genet 2003, 72:270-280.

12. Meijers-Heijboer $\mathrm{H}$, Wijnen J, Vasen $\mathrm{H}$, Wasielewski M, Wagner A, Hollestelle A, Elstrodt F, Van Den BR, De SA, Fat GT, et al: The CHEK2 1100delC mutation identifies families with a hereditary breast and colorectal cancer phenotype. Am J Hum Genet 2003, 72:1308-1314.

13. Walsh T, Casadei S, Lee MK, Pennil CC, Nord AS, Thornton AM, Roeb W, Agnew KJ, Stray SM, Wickramanayake A, et al: Mutations in 12 genes for inherited ovarian, fallopian tube, and peritoneal carcinoma identified by massively parallel sequencing. Proc Natl Acad Sci USA 2011, 108:18032-18037.

14. The CHEK2 Breast Cancer Case-control Consortium: CHEK2*1100delC and susceptibility to breast cancer: a collaborative analysis involving 10,860 breast cancer cases and 9,065 controls from 10 studies. Am J Hum Genet 2004, 74:1175-1182.

15. Weischer M, Bojesen SE, Ellervik C, Tybjaerg-Hansen A, Nordestgaard BG: CHEK2*1100delC genotyping for clinical assessment of breast cancer risk: meta-analyses of 26,000 patient cases and 27,000 controls. J Clin Oncol 2008, 26:542-548. 
16. Shaag A, Walsh T, Renbaum P, Kirchhoff T, Nafa K, Shiovitz S, Mandell JB, Welcsh $P$, Lee MK, Ellis N, et al: Functional and genomic approaches reveal an ancient CHEK2 allele associated with breast cancer in the Ashkenazi Jewish population. Hum Mol Genet 2005, 14:555-563.

17. Bogdanova N, Enssen-Dubrowinskaja N, Feshchenko S, Lazjuk Gl, Rogov YI, Dammann O, Bremer M, Karstens JH, Sohn C, Dork T: Association of two mutations in the CHEK2 gene with breast cancer. Int J Cancer 2005, 116:263-266.

18. Cybulski C, Wokolorczyk D, Huzarski T, Byrski T, Gronwald J, Gorski B, Debniak T, Masojc B, Jakubowska A, van de Wetering T, et al: A deletion in CHEK2 of 5,395 bp predisposes to breast cancer in Poland. Breast Cancer Res Treat 2007, 102:119-122.

19. Novak DJ, Chen LQ, Ghadirian P, Hamel N, Zhang P, Rossiny V, Cardinal G, Robidoux A, Tonin PN, Rousseau F, et al: Identification of a novel CHEK2 variant and assessment of its contribution to the risk of breast cancer in French Canadian women. BMC Cancer 2008, 8:239.

20. Zhang S, Phelan CM, Zhang P, Rousseau F, Ghadirian P, Robidoux A, Foulkes W, Hamel N, McCready D, Trudeau M, et al: Frequency of the CHEK2 1100 delC mutation among women with breast cancer: an international study. Cancer Res 2008, 68:2154-2157.

21. Bell DW, Kim SH, Godwin AK, Schiripo TA, Harris PL, Haserlat SM, Wahrer DC, Haiman CA, Daly MB, Niendorf KB, et al: Genetic and functional analysis of CHEK2 (CHK2) variants in multiethnic cohorts. Int J Cancer 2007, 121:2661-2667.

22. Chen W, Yurong S, Liansheng N: Breast cancer low-penetrance allele 1100delC in the CHEK2 gene: not present in the Chinese familial breast cancer population. Adv Ther 2008, 25:496-501.

23. Choi DH, Cho DY, Lee MH, Park HS, Ahn SH, Son BH, Haffty BG: The CHEK2 1100 delC mutation is not present in Korean patients with breast cancer cases tested for BRCA1 and BRCA2 mutation. Breast Cancer Res Treat 2008, 112:569-573.

24. de Jong MM, Van der Graaf WTA, Nolte IM, Te Meerman GJ, Oosterwijk JC, Van der Steege G, Boezen M, Schaapveld M, Kleibeuker JH, De Vries EGE: Increased CHEK2 1100delC genotype frequency (also) in unselected breast cancer patients [abstract]. J Clin Oncol 2004, 22(Suppl 14):S844.

25. Desrichard A, Bidet Y, Uhrhammer N, Bignon YJ: CHEK2 contribution to hereditary breast cancer in non-BRCA families. Breast Cancer Res 2011, 13:R119.

26. Kilpivaara O, Vahteristo P, Falck J, Syrjakoski K, Eerola H, Easton D, Bartkova J, Lukas J, Heikkila P, Aittomaki K, et al: CHEK2 variant I157T may be associated with increased breast cancer risk. Int J Cancer 2004 111:543-547.

27. Kuusisto KM, Bebel A, Vihinen M, Schleutker J, Sallinen SL: Screening for BRCA1, BRCA2, CHEK2, PALB2, BRIP1, RAD50, and CDH1 mutations in high-risk Finnish BRCA1/2-founder mutation-negative breast and/or ovarian cancer individuals. Breast Cancer Res 2011, 13:R20.

28. Lee AS, Ang P: CHEK2*1100delC screening of Asian women with a family history of breast cancer is unwarranted. J Clin Oncol 2008, 26:2419-2420.

29. Rajkumar T, Soumittra N, Nancy NK, Swaminathan R, Sridevi V, Shanta V: BRCA1, BRCA2 and CHEK2 (1100 del C) germline mutations in hereditary breast and ovarian cancer families in South India. Asian Pac J Cancer Prev 2003, 4:203-208

30. Soumittra N, Meenakumari B, Parija T, Sridevi V, Nancy KN, Swaminathan R, Rajalekshmy KR, Majhi U, Rajkumar T: Molecular genetics analysis of hereditary breast and ovarian cancer patients in India. Hered Cancer Clin Pract 2009, 7:13.

31. Thirthagiri E, Cheong LS, Yip CH, Teo SH: CHEK2*1100delC does not contribute to risk to breast cancer among Malay, Chinese and Indians in Malaysia. Fam Cancer 2009, 8:355-358.

32. Song CG, Hu Z, Yuan WT, Di GH, Shen ZZ, Huang W, Shao ZM: CHEK2 c.1100delC may not contribute to genetic background of hereditary breast cancer from Shanghai of China. Zhonghua Yi Xue Yi Chuan Xue Za Zhi 2006, 23:443-445.

33. Hollestelle A, Wasielewski M, Martens JW, Schutte M: Discovering moderate-risk breast cancer susceptibility genes. Curr Opin Genet Dev 2010, 20:268-276

34. Bogdanova N, Feshchenko S, Cybulski C, Dork T: CHEK2 mutation and hereditary breast cancer. J Clin Oncol 2007, 25:e26.

35. Sokolenko AP, Rozanov ME, Mitiushkina NV, Sherina NY, lyevleva AG, Chekmariova EV, Buslov KG, Shilov ES, Togo AV, Bit-Sava EM, et al:
Founder mutations in early-onset, familial and bilateral breast cancer patients from Russia. Fam Cancer 2007, 6:281-286.

36. Walsh T, Casadei S, Coats KH, Swisher E, Stray SM, Higgins J, Roach KC, Mandell J, Lee MK, Ciernikova S, et al: Spectrum of mutations in BRCA1, BRCA2, CHEK2, and TP53 in families at high risk of breast cancer. JAMA 2006, 295:1379-1388.

37. Liu Y, Liao J, Xu Y, Chen W, Liu D, Ouyang T, Li J, Wang T, Fan Z, Fan T, et al: A recurrent CHEK2 p.H371Y mutation is associated with breast cancer risk in Chinese women. Hum Mutat 2011, 32:1000-1003.

38. Rashid MU, Zaidi A, Torres D, Sultan F, Benner A, Naqvi B, Shakoori AR, Seidel-Renkert A, Faroog H, Narod S, et al: Prevalence of BRCA1 and BRCA2 mutations in Pakistani breast and ovarian cancer patients. Int J Cancer 2006, 119:2832-2839.

39. Rashid MU, Gull S, Asghar K, Muhammad N, Amin A, Hamann U: Prevalence of TP53 germ line mutations in young Pakistani breast cancer patients. Fam Cancer 2012, 11:307-311.

40. Sodha N, Houlston RS, Williams R, Yuille MA, Mangion J, Eeles RA: A robust method for detecting CHK2/RAD53 mutations in genomic DNA. Hum Mutat 2002, 19:173-177.

41. Dufault MR, Betz B, Wappenschmidt B, Hofmann W, Bandick K, Golla A, Pietschmann A, Nestle-Kramling C, Rhiem K, Huttner C, et al: Limited relevance of the CHEK2 gene in hereditary breast cancer. Int $J$ Cancer 2004, 110:320-325

42. Kleibl Z, Havranek O, Novotny J, Kleiblova P, Soucek P, Pohlreich P: Analysis of CHEK2 FHA domain in Czech patients with sporadic breast cancer revealed distinct rare genetic alterations. Breast Cancer Res Treat 2008, 112:159-164.

43. Le Calvez-Kelm F, Lesueur F, Damiola F, Vallee M, Voegele C, Babikyan D, Durand G, Forey N, Kay-Chopin S, Robinot N, et al: Rare, evolutionarily unlikely missense substitutions in CHEK2 contribute to breast cancer susceptibility: results from a breast cancer family registry case-control mutation-screening study. Breast Cancer Res 2011, 13:R6.

44. Osorio A, Rodriguez-Lopez R, Diez O, de la Hoya M, Ignacio MJ, Vega A, Esteban-Cardenosa E, Alonso C, Caldes T, Benitez J: The breast cancer low-penetrance allele $1100 \mathrm{delC}$ in the CHEK2 gene is not present in Spanish familial breast cancer population. Int J Cancer 2004, 108:54-56

45. Laitman Y, Kaufman B, Lahad EL, Papa MZ, Friedman E: Germline CHEK2 mutations in Jewish Ashkenazi women at high risk for breast cancer. Isr Med Assoc J 2007, 9:791-796.

46. Schutte M, Seal S, Barfoot R, Meijers-Heijboer H, Wasielewski M, Evans DG, Eccles D, Meijers C, Lohman F, Klijn J, et al: Variants in CHEK2 other than 1100 delC do not make a major contribution to breast cancer susceptibility. Am J Hum Genet 2003, 72:1023-1028.

47. Xiao W, Oefner PJ: Denaturing high-performance liquid chromatography: A review. Hum Mutat 2001, 17:439-474

48. Cybulski C, Huzarski T, Byrski T, Gronwald J, Debniak T, Jakubowska A, Gorski B, Wokolorczyk D, Masojc B, Narod SA, et al: Estrogen receptor status in CHEK2-positive breast cancers: implications for chemoprevention. Clin Genet 2009, 75:72-78.

49. De Bock GH, Schutte M, Krol-Warmerdam EM, Seynaeve C, Blom J, Brekelmans CT, Meijers-Heijboer H, van Asperen CJ, Cornelisse CJ, Devilee P, et al: Tumour characteristics and prognosis of breast cancer patients carrying the germline CHEK2*1100delC variant. J Med Genet 2004 41:731-735

50. Domagala P, Wokolorczyk D, Cybulski C, Huzarski T, Lubinski J, Domagala W: Different CHEK2 germline mutations are associated with distinct immunophenotypic molecular subtypes of breast cancer. Breast Cancer Res Treat 2012, 132:937-945.

51. Huzarski T, Cybulski C, Domagala W, Gronwald J, Byrski T, Szwiec M, Woyke S, Narod SA, Lubinski J: Pathology of breast cancer in women with constitutional CHEK2 mutations. Breast Cancer Res Treat 2005, 90:187-189.

doi:10.1186/1471-2407-13-312

Cite this article as: Rashid et al: Constitutional CHEK2 mutations are infrequent in early-onset and familial breast/ovarian cancer patients from Pakistan. BMC Cancer 2013 13:312. 